\title{
A IMPORTÂNCIA DO LÚDICO NA EDUCAÇÃO INFANTIL
}

\author{
Daniele Raimundo dos Anjos Gonçalves \\ Maria de Fatima Gomes Passos \\ Leandra de Souza Alves \\ Denise Raimundo dos Anjos Gonçalves \\ Wilma Raimundo dos Anjos Gonçalves \\ Diogenes José Gusmão Coutinho
}

\begin{abstract}
RESUMO: Este trabalho teve como seu principal objetivo analisar a importância do lúdico na educação Infantil e no processo de ensino e de aprendizagem da criança, o brincar permite com que a criança aprenda a lidar com as suas emoções, equilibrar suas tensões, provenientes de seu mundo cultural, auxiliando assim na construção de sua individualidade. O objetivo desse trabalho é abordar a importância do lúdico no processo de educação-aprendizagem, buscando compreender a relevância do brincar na construção do desenvolvimento e de aprendizagem na educação dessas crianças. Foi realizada uma pesquisa bibliográfica baseada nos fundamentos de autores como Piaget, Vigotsky, e Cunha. Buscando identificar o lúdico aliado a atividades pedagógicas, promovendo uma forma prazerosa de aprender.
\end{abstract}

Palavras chave: Criança. Brincar. Aprender.

ABSTRACT: This work had as its main objective to analyze the importance of playfulness in early childhood education and in the child's teaching and learning process, playing allows children to learn to deal with their emotions, balance their tensions, arising from their cultural world, thus helping to build their individuality. The objective of this work is to approach the importance of playfulness in the education-learning process, seeking to understand the relevance of playing in the construction of development and learning in the education of these children. A bibliographical research was carried out based on the foundations of authors such as Piaget, Vigotsky, and Cunha. Seeking to identify the playful allied to pedagogical activities, promoting a pleasurable way of learning.

Keywords: Child. Play. Learn.

\section{INTRODUÇÃO}

A Educação Infantil possui características e necessidades específicas, é um período importante para formação do ser humano e nesse nível de ensino, é importante valorizar as vivências e o mundo das crianças, utilizando atividades próprias da cultura infantil (atividades lúdicas e imaginativas) que possam garantir a motivação e o interesse das crianças, as brincadeiras são extremamente importantes para o desenvolvimento da 
criatividade da criança, proporcionando o conhecimento, de seu corpo, de sua história e para o conhecimento do mundo.

O através das brincadeiras, a criança constrói novas formas de atuar consigo, com o outro e com o meio. A brincadeira permite a criança entrar em um mundo onde tudo pode ser possível dentro do que é real.

Assim, a ludicidade deve ser usada de forma a significativa, ajudando o aluno a construir sua identidade, entender sua realidade, despertando sua curiosidade e motivandoo para a construção do mundo em que vive.

Este trabalho de pesquisa busca refletir sobre a importância do trabalho com o lúdico, tendo como objetivo identificar e relacionar como a utilização de atividades lúdicas no contexto da educação infantil é fundamental para o desenvolvimento do ser humano.

O trabalho no contexto da educação infantil foi desenvolvido e estruturado em uma pesquisa bibliográfica, tendo autores como Vigotsky, Frobel e Cunha como base para uma discursão de como acontece à aprendizagem escolar com brincadeiras. $O$ valor dessas brincadeiras no desenvolvimento do conhecimento da criança, e como essas atividades ajudam a criança a aprender melhor.

\section{O VALOR DO BRINCAR}

Quando a criança brinca, um mundo de conhecimento a percorre e ela mergulha em sua atividade lúdica e organiza todo o seu ser em função da sua ação. Na maioria das vezes observamos pouco às crianças brincando, se os educadores pararem para dar ênfase a esta importância perceberão e aprenderão muito sobre elas, e principalmente sobre os caminhos que levam o ser humano à construção da sua Inteligência, do seu conhecimento e da sua felicidade. E tão fundamental o brincar para a criança que quanto mais ela interage no brincar mais ela exercitará sua capacidade de concentrar a atenção, de descobrir, de criar e de permanecer em atividade. Ela aprenderá a engajar-se, seriamente, gratuitamente, pelo que está fazendo no momento explorado, por esta razão que o este momento é tão importante, pois nele se cultiva qualidades raras e fundamentais.

A convivência com outras crianças pode ser muito enriquecedora, pois elas estimulam e fortalecem tanto a autonomia quanto o crescimento. A educação é um processo que acontece na interação entre as pessoas e o ambiente em que vivem. Todo ser humano 
necessita de momentos para encontrar-se, para harmonizar suas energias e poder alcançar seu equilíbrio, e a vida interior da criança é centrada no brincar.

É brincado que ela expressa sentimentos, emoções, e suas habilidades que ela mesma desconhece, é brincando que ela manifesta suas potencialidades e explora suas artes, é através de suas experiências mais variadas que vai aprendendo a viver, amadurecendo e libertando-se de seus medos de dentro para fora, lentamente adquirindo segurança que só as coisas naturais e verdadeiras oferecem. Este processo é tão lindo, tão mágico que tem seu ritmo próprio, acelerá-lo pode prejudicar a ponto de impedir e interferir no processo de desenvolvimento.

Se este momento (brincar) da criança for respeitado, isso acarretará no seu futuro, pois passará do brincar para trabalhá-lo sem perceber, e ela continuará sentindo o mesmo prazer na atividade. Diz o ditado que: homem feliz é o que gosta do que faz. Brincar? Trabalhar?

A brincadeira é tão importante na vida do ser humano que em todas as fases ele brinca de modo geral. Seja o adolescente com suas brincadeiras para chamara atenção, os jovens

para descontrair, os adultos para fugir das rotinas diárias do trabalho e do estresse, e até mesmo os idosos que voltam ao tempo com as brincadeiras para se distrair e melhor viver. Toda a brincadeira faz parte da nossa vida.

O valor de uma brincadeira envolve diversos âmbitos e situações na vida de uma criança enquanto brinca dentre elas estão as mais conhecidas: a casinha, uma inocente brincadeira de criança trás consigo uma excelente bagagem de material para trabalhar e desenvolver valores estabelecer relações amigáveis, o faz de contas de ser pai e mãe faz a criança aprender as responsabilidades que ela deve adquirir, e também o relacionamento entre família essência como primordial tal como na escola ou na sociedade e que ela vive.

\section{I.I. O brincar desenvolvendo conhecimento da criança}

$\mathrm{O}$ ato de brincar acontece em determinados momentos do cotidiano infantil, neste momento percebesse que brincar deve ser algo comum em nossa vida ou pelo menos deveria ser.

Segundo o Oliveira 2009 o brincar não significa a pessoa recrear é muito mais se caracterizando como uma das formas mais complexas, que a criança tem de se se comunica 
comigo mesma e com o mundo. Como uma grande troca de aprendizagem prazerosa não sendo somente lazer, mas sim, um ato de aprendizagem durante maturação.

"Para Vygotsky, citado por barquero (1998), a brincadeira, o jogo, são atividades especificas da infância, nas quais a criança recreia a realidade usando" O brincar é uma necessidade básica e um direito de todos. O brincar é uma experiência humana, rica de conhecimentos. As crianças aprendem com mais eficácia a partir do momento que elas sentem prazer em prender. Nesse sentido, espera-se que os educadores reflitam e reconheçam a importância que as atividades lúdicas têm em assegurar a eficácia do processo ensino- aprendizagem.

O lúdico promove rendimento escolar além do conhecimento, oralidade, pensamento e o sentido.

\subsection{Brincar na escola ajuda a criança a aprender melhor}

A escola é um lugar como outro qualquer, mas também tem como objetivo proporcionar o conhecimento formal e o desenvolvimento dos processos do pensamento ao aluno é na escola que a criança aprende a formar opiniões, tornando-se um cidadão crítico.

Não cabe à escola, contudo repetir o cotidiano que a criança vivencia fora dela, mas incluir o brincar na escola tem como fundamental importância, dois aspectos essenciais na vida dela, servir ao desenvolvimento enquanto indivíduo e à construção do conhecimento, um processo interligado e que andam em comum acordo.

Quando se fala de brincar, vem então, a responsabilidade deste grande conceito, pois não é simplesmente perder tempo, ou gastar a energia da criança, este momento da brincadeira na escola não é exatamente igual a brincar em outras ocasiões. A imposição de tarefas exaustivas as incompatibilidades de horários, e os pais são outros fatores que podem impedir as brincadeiras livres.

É função de a escola levar a criança a obter experiências que a ajudem e a estimulem no seu crescimento e em seu repertório escolar, bem como os conhecimentos que a criança já detém. O brincar como forma de atividade nada mais é que uma forma de atividade humana e tem grande predomínio na infância, onde encontra seu lugar no processo educativo, pois a sua utilização é fundamental e promove o desenvolvimento dos processos 
psíquicos; dos movimentos, acarretando os conhecimentos do próprio corpo, da linguagem e da aprendizagem de conteúdo, tanto nas áreas humanas quanto nas áreas exatas.

Todo professor precisa procurar métodos, ou seja, meios que ajudem as crianças a tornar a escola seu meio de prazer e não de obrigação, tornar aquele momento escolar construtivo para seu crescimento. As atividades lúdicas geralmente ocupam momentos determinados de seu planejamento e é um facilitador de aprendizagem dos alunos. A ação do educador deve ser antes de tudo, refletida, planejada e uma vez executada e avaliada para melhor resultado.

O brincar da criança, aqui apresentado, precisa ser levado em consideração como fator chave no processo de aprendizagem do aluno e tem que ter seu tempo determinado explorando, sentimentos, ações, reações deles, e não simplesmente considerado uma atividade complementar pedagógica.

O brinquedo fornece ampla estrutura básica para mudanças das necessidades e da consciência. A ação na esfera imaginativa, numa situação imaginária, a criação das intenções voluntárias e a formação dos planos da vida real e motivações volitivas - tudo aparece no brinquedo, que se constitui, no mais alto nível de desenvolvimento pré-escolar. A criança desenvolve-se, essencialmente, através da atividade de brinquedo. Somente neste sentido o brinquedo pode ser considerado uma atividade que determina o desenvolvimento da criança. (VYGOTSKY, 1984 p.I17)

\section{I.3. O brincar e suas relações com o aprendizado}

A abordagem de VIGOTSKY (1933/1998; Vigotsky. Luria \& Leontiev. 1998) é histórico-cultural, uma vez que a ênfase está nas qualidades que distinguem a espécie humana das demais: transformações e realizações ativas aos diferentes contextos culturais e históricos. Nesta perspectiva, tanto as estruturas sociais como as estruturas mentais têm raízes bem definidas como produtos bastante específicos de níveis determinados do desenvolvimento humano.

Ou seja, tem a ver com a relação que os homens estabelecem diariamente, tanto entre si, como com a natureza. Isso é bastante importante, pois nenhum homem jamais conseguirá viver sozinho sem o contato com outros ou com a natureza. VIGOTSKY (1933/1998) destaca a fundamental característica do brincar diretamente associada ao desenvolvimento: a de intermediar a necessária transição entre estágios de desenvolvimento metal. O brinquedo trás uma relação forte com o desenvolvimento proximal. 
O brincar é uma atividade regida por um processo de fases do desenvolvimento infantil através de grupos de brincadeiras, sendo eles: o primeiro grupo são aqueles que as crianças brincam com objetos como chocalho, lança e apanha objetos. Em grupo seguinte são aquelas que as crianças se escondem e foge, a imitação também prevalece, e por fim da idade pré-escolar inicia-se o jogar com regras.

Torna-se então necessário considerar brinquedos e brincadeiras na escola como fator agravante da relação que ele tem com a aprendizagem do aluno, o desenvolvimento e as questões relacionadas a vida social e cultural da criança. Contudo, além dos significados comuns a determinadas faixas etárias ,há ainda, a possibilidade de que a brincadeira tenha um significado único para cada uma das crianças em particular. É exatamente o brincar que pode mostrar ,com mais clareza, as transições do desenvolvimento. Entretanto, não se pode esquecer que o brincar está fortemente vinculado à cultura e à subjetividade da criança PEREIRA,2004.

Portanto fica clara a importância do brincar na vida de uma criança. Logo o autor retifica ao dizer:

A brincadeira é uma atividade espiritual mais pura do homem neste estágio e, ao mesmo tempo, típica da vida humana enquanto um todo da vida natural interna no homem e de todas as coisas. Ela dá alegria, liberdade, contentamento, descanso externo e interno, paz com o mundo... A criança que brinca sempre, pode certamente torna-se um homem determinado, capaz de autosacrificio para a promoção de seu bem e dos outros... Como sempre indicamos o brincar em qualquer tempo não é trivial, é altamente sério e de profunda significação (Frobel I9I2c p. 55).

\section{A IMPORTÂNCIA DA BRINCADEIRA NA EDUCAÇÃO INFANTIL}

\section{PARA QUE BRINCAR? QUE IMPORTÂNCIA ISSO TEM NA VIDA E NO APRENDIZADO DE UMA CRIANÇA?}

Nenhuma expressaria melhor esta questão do que levar em consideração a necessidade e a importância de explorar a brincadeira na vida escolar de uma criança, como fator fundamental para seu desenvolvimento-aprendizagem que os alunos extraem: (motor, social, psíquico, emocional, racional, psíquico, emocional, racional).Pois durante muito tempo, os jogos e brincadeiras foram negligenciados, sobretudo pela escola, pois eram considerados desprovidos de qualquer significado funcional. No entanto, a pedagogia moderna uma escola de superação como base na participação ativa do aluno no processo de 
ensino-aprendizagem, redescobriu a necessidade e a importância desses elementos na atividade didática. As brincadeiras alimentam antes de tudo, o espírito imaginativo, exploratório e inventivo do faz de conta e a isso chamamos de: LÚDICO.

Para a psicologia, o ato de brincar merece destaque no aspecto do significado que a brincadeira tem na formação da pessoa, isto é, cada gesto e palavras observados trazem em elementos que diferem de quem está ou não brincando. $\mathrm{Na}$ pedagogia, as brincadeiras tem sido alvo de muitos estudos, e principalmente como instrumentos pedagógicos. Há um novo e importante processo psicológico para a criança, processo de imaginação, que lhe permite desprender-se das restrições impostas pelo ambiente imediato.

A criança é agora capaz de modificar o significado dos objetos, transformando uma coisa em outra, assim o campo de significado se impõe sobre o campo perceptual. A gênese do processo do brincar está naquilo que a criança conhece e vivência; e é com base nessas experiências que a criança reelabora situações de sua vida cotidiana, combina e cria novas realidades, desempenha papéis que vivencia (filho/filha),papéis que ainda não pode ser (mãe/pai)papéis que aspira ser(cantor/ator) e papéis que a sociedade condena(ladrão/bêbado etc.).

Refletindo com suas relações com esses "outros”, vivenciando esses outros, a criança toma consciência de si e do mundo, construindo assim o significado sobre a realidade.

De acordo com VYGOTSKY (1987), no início da vida da criança, sua ação sobre o mundo é determina pelo contexto perceptual e pelos objetos nele contido.

\subsection{Brincar é coisa séria!}

A brincadeira proporciona à criança a interação com o outro, a ter um papel extremamente importante na aquisição de linguagem, na capacidade de perceber o outro, de colocar-se no papel do outro, real ou imaginário (eu sou um pai, um policial ou um médico).

“A criança e o adolescente têm direito à liberdade, ao respeito, e à dignidade como pessoas humanas em processo de desenvolvimento...".

O direito está garantido pelo $15^{\circ}$ artigo do Estatuto da Criança e do Adolescente. No parágrafo seguinte, num dos significados do direito à liberdade, está escrita a questão do "brincar", praticar esporte e diverte-se. Brincar nunca foi levado a sério. No mundo cada vez mais competitivo no qual as crianças desde cedo, precisam trabalhar para ajudar no sustento 
da família, e obter êxito profissional, as crianças em si carregam tal responsabilidade que nem tem tempo para brincar. Quando estimulamos uma criança a brincar estamos alargando seu projeto de desenvolvimento

\footnotetext{
"Brincar desenvolve as habilidades da criança de forma natural, pois brincando aprende a socializar-se com outras crianças, desenvolve a motricidade, a mente, a criatividade, sem cobrança ou medo, mas sim com prazer" (Cunha 20oI, p.I4)
}

O brincar é tão importante que ajuda na linguagem essencial da criança, ou seja, ele facilita o desenvolvimento oral e cognitivo bem como contribui para seu processo de socialização e auto expressão, nela a criança possui a necessidade de se comunicar com o mundo, expressar sentimentos, conviver com as diferenças sociais e conhecer seu próprio corpo.

Que criança não gosta de brincar brincando ela desenvolve seus sentimentos, dependendo de motivações.

Além disso, brincar também ajuda criança a falhar de forma correta e a interagir com seus colegas. As variedades de brincadeiras possibilitam melhor desenvolvimento nas atividades propostas no dia a dia com palavras novas a se organizar e a coordenação das crianças aprende a compartilhar as suas coisas, a respeitar os direitos dos outros, o espaço buscando sentido para cada vida. Ela compara, compreende, calcula, classifica, compõe. Muito mais que entreter e distrair, as brincadeiras têm a função de ajudar o desenvolvimento da criança, aumenta o alto estima ao seu ser.

\section{BRINCAR OU ESTUDAR?}

É uma questão que tem provocado bastante posicionamento entre envolvidos no processo Pais/ Professores. Existe hora para tudo, hora de brincar, e hora de estudar, certamente você já ouviu isso. Está embutido nesta fala o entendimento de que brinquedo em nada ou muito pouco contribui para aprendizagem. O contrário também acontece: com o intuito de imprimir um sentido de seriedade, onde as escolas introduzem o lápis e o papel de forma massiva, ocupando quase a totalidade do tempo com atividades de contornar, pintar/desenhos. 
A idéia embutida é que aspectos cognitivos se desenvolvem através de atividades como ler e escrever. Porém devemos sair da mesmice e levar em consideração a brincadeira como coisa séria! Pois é uma forma de atividade complexa.

Sendo assim, precisamos enquanto profissionais, nos munir de argumentos favoráveis ao respeito e ao direito da criança à brincadeira, ao lúdico e conseqüentemente, a infância. Dessa forma, levantaremos vários pontos indicativos para efetivarmos esta concepção.

A oposição entre a brincadeira é "coisa séria" é quase inexistente para as crianças pequenas as de educação infantil. O esforço e concentração despendida pela criança em atividades lúdicas são similares ao que é dependido para aprender a andar, falar, comer e mais tarde, ler, escrever, contar... Pois o brinquedo/ brincar ajuda as crianças independentemente de época, cultura, raça ou classe social, ela simplesmente é uma chave de desenvolvimento psicológico. Assim, “O BRINCAR E ESTUDAR” se farão claramente associados, resultando na positividade se interações pedagógicas.

\section{BRINCADEIRA É CULTURA}

Brincar também é cultura, pois sabemos que existem vários tipos de brincadeiras desde a antiguidade, em como sabemos já da importância da brincadeira, ela trás consigo uma bagagem de tradicionalismo e cultura onde até hoje algumas delas prevalecem à cultura social e permeia até os dias de hoje, infelizmente a tecnologia tem roubado o tempo das crianças e até mesmo o desejo das brincadeiras antigas que são de fundamental importância para o crescimento delas, até mesmo por ter sido de gerações antigas dentre elas estão: Brincar de pira, pique-pega, salva, barata, maruja, pegador, jogar peteca, amarelinha, piqueesconde, cabra cega, bolinha de gude, cinco pedrinha, bole-bole, bugalha, cinco-Marias, saquinhos, almofadinhas, pular sela, canguru, estrela-novo-toco, escravos de Jô, chicotequeimado, peia-quente, cipozinho, queimado, esconde-vareta, quente-frio, rato-na-toca, entre outras. $O$ que se esconde sob esses nomes diversificados é, ao mesmo tempo, a universalidades da brincadeira enquanto prática cultural. Brincadeiras são como rituais que se transmite, repetidos ou recriados, em ambientes socioculturais ou escolares para o desenvolvimento da aprendizagem da criança. "Brincadeira é cultura" Ana M.A.Carvalho Fernando A.R. Pontes 
Ao anoitecer brincamos as cinco pedrinhas no degrau da porta de casa, graves como convém a um deus e a u poeta, como se cada pedra fosse todo o universo, e fosse por isso um grande perigo para ela deixá-lo cair no chão. Fernando Pessoa.

Ao longo da evolução e da tecnologia as crianças estão perdendo o prazer das brincadeiras naturais e se distraindo apenas com jogos de tecnologia onde elas perdem a essência do conhecimento e a descoberta de novas idéias além socializar-se com outras crianças a construção de conhecimento psicológico. E preciso resgatar nelas o desejo do brincar natural.

Agora é o tempo das pipas. Não tem dia marcado. Dá na gente aquela vontade de brincar... Quando a gente sente isso, começa a procurar o bambu pra fazer as varetas. E o outro menino já pensou também, e todo mundo começa, aí é o tempo da pipa”. Menino de Carapicuíba, SP.

\section{METODOLOGIA}

O presente trabalho se ancorou e base de pesquisas bibliográficas, tendo como fase inicial a seleção de matéria, possibilitando ter como base e apoio de teóricos renomados como: Piaget, Vigotsky (1998), Citações de Cunha (200I) e entre outros, fazendo a seguida leitura e releitura desse material elaborado pela aluna.

No que se refere à metodologia de jogos, brincadeiras, ou seja, a importância do lúdico no desenvolvimento da criança fundamentou-se em livros, revistas, artigos e sites de internet, sempre se se baseando no tema de pesquisa e nas experiências como docente.

O presente tema foi escolhido com o intuito de ajudar a aluna a refletir mediante a realidade vivenciada nos estágios curriculares da fundamental importância do lúdico na educação infantil, visando a melhoria e o desenvolvimento educacional e aprendizagem da criança no âmbito escola. Finalizando a conclusão do Trabalho.

\section{CONSIDERAÇÕES FINAIS}

Uma grande parte das pessoas tem didatizado à atividade lúdica ao encontrar na própria vida, mas pessoas reais, presente no nosso cotidiano a sua valorização é importante, principalmente, na infância na fase de aprendizado.

É muito importante registrar que Vygtsky usava a terminologia brinquedo e Piaget a terminologia jogo para conceituar a ação de brincar, a ludicidade. 
O lúdico se faz presente em todo espaço em que as pessoas de um grupo estão para que se faça a ludicidade é importante esse processo e o brinquedo e os jogos são grandes aliados necessários para tornar a aprendizagem prazerosa.

\section{REFERÊNCIAS BIBLIOGRÁFICAS}

CUNHA, Nylse Helena da Silva. Brinquedo, desafio e descoberta para Utilização e confecção de brinquedos. Rio de Janeiro: Fae, 1988. Brinquedoteca: Um mergulho no brincar. $3^{\mathrm{a}}$ ed. São Paulo: Vetor, 200 .

DORNELES, Maria. A Ludicidade na Educação Infantil: Uma atitude pedagógicaz. Ed. IBEPEX, dialógica

FROEBEL, F. Pedagogics of the Kindergarten - or his ideas concerning the play and plaything of the child. HARRIS, W.T. (Ed). The international series. New ork/London: D. Appleton and Company, i9i2. vol 30.

PIAGET, J. INHELDER, B. A psicologia da criança. São Paulo: Difusão, 1986.

Referencial curricular nacional para a educação infantil / Ministério da Educação e do Desporto, Secretaria de Educação Fundamental. - Brasília: MEC/SEF, 1998.

VIGOTSKY, L. S. A formação social da mente. São Paulo: Martins Fontes, 1984.

VYGOTSKI, L.S. et al. Linguagem, desenvolvimento e aprendizagem. São Paulo: Ícone/Edusp, 1999. 